\title{
QUALIDADE DO CARVÃO VEGETAL PARA O CONSUMO DOMÉSTICO COMERCIALIZADO NA REGIÃO SERRANA SUL DE SANTA CATARINA ${ }^{1}$
}

Martha Andreia Brand ${ }^{2}$, Aline Almada Rodrigues ${ }^{3}$, Alberto de Oliveira ${ }^{4}$, Mauro Silveira Machado ${ }^{4}$ e Linéia Roberta $\mathrm{Zen}^{5}$

\begin{abstract}
RESUMO - Este trabalho teve como objetivo averiguar a qualidade do carvão vegetal para consumo doméstico, comercializado na região Serrana Sul de Santa Catarina. Foram coletadas 12 marcas de carvão na região da Associação dos Municípios da Região Serrana (AMURES) e Curitibanos. Foram descritas e analisadas as características gerais das embalagens e determinadas as propriedades físicas e energéticas de cada uma das marcas. As propriedades analisadas foram: densidade relativa aparente, teor de umidade, poder calorífico, teor de carbono fixo, voláteis e cinzas. As marcas comercializadas na região são oriundas dos Estados de Santa Catarina, Rio Grande do Sul e Paraná. A acácia-negra e os eucaliptos são as espécies mais usadas para a produção de carvão. Não existe padronização das informações nas embalagens. O carvão vegetal apresentou densidade relativa aparente alta $\left(0,403 \mathrm{~g} / \mathrm{cm}^{3}\right)$; teor de umidade alto $(7,35 \%)$; poder calorífico superior médio de $6.449 \mathrm{kcal} / \mathrm{kg}$, com muita variação entre as amostras; alto teor de voláteis e cinzas; e baixo teor de carbono fixo $(32,85 \%, 1,96 \%$ e $65,17 \%$, respectivamente). A produção e consumo do carvão vegetal no Planalto Sul catarinense são regionalizados, sem padronização das embalagens e com registro nos órgãos ambientais de fiscalização. A qualidade do carvão comercializado na região é baixa.
\end{abstract}

Palavras-chave: Densidade relativa aparente; Poder calorífico superior; Churrasco.

\section{QUALITY OF CHARCOAL FOR DOMESTIC CONSUPTION MARKETED IN THE SOUTHERN HIGHLANDS REGION OF SANTA CATARINA}

\begin{abstract}
This study aimed to determine the quality of charcoal for domestic consumption, marketed in the southern mountain region of Santa Catarina. Twelve brands of charcoal sold in the AMURES (Association of Municipalities of the Mountain Region) and Curitibanos region were collected. The general characteristics of packaging and certain physical and energetic properties of each of the brands were described and analyzed. The properties analyzed were: apparent relative density, moisture content, calorific value, fixed carbon content, volatile and ash. The brands sold in the region are from the states of Santa Catarina, Rio Grande do Sul and Parana. The black wattle and eucalyptus are most commonly used for the production of charcoal. There is no standard information in packagings. The charcoal showed high relative density $\left(0.403 \mathrm{~g} / \mathrm{cm}^{3}\right) ;$ high moisture content (7.35\%); with an average gross calorific value of $6449 \mathrm{kcal} / \mathrm{kg}$, with a lot of variation between samples; high volatile and ash content and low fixed carbon content $(32.85 \%, 1.96 \%$ and $65.17 \%$, respectively). The production and consumption of charcoal in southern Santa Catarina plateau is regionalized, without standardization of packaging and with records in environmental supervisory bodies. The quality of charcoal sold in the region is low.
\end{abstract}

Keywords: Relative density; Gross calorific value; Barbecue.

\footnotetext{
${ }^{1}$ Recebido em 06.11.2014 aceito para publicação em 13.10.2015.

${ }^{2}$ Universidade do Estado de Santa Catarina, Centro Agroveterinário, Departamento de Engenharia Florestal, Lages, SC Brasil.E-mail: <a2mab@cav.udesc.br>.

${ }^{3}$ Universidade Estadual do Mato Grosso do Sul, Graduando em Engenharia Florestal, Aquidauana, MS, Brasil. E-mail: <martha.brand@udesc.br>.

${ }^{4}$ Universidade do Estado de Santa Catarina, Programa de Mestrado em Engenharia Florestal, Lages, SC - Brasil. E-mail: <ado.beto@hotmail.com>e <mauro_s_machado@hotmail.com>.

${ }^{5}$ Universidade Federal do Paraná, Programa de Pós-graduação em Engenharia Florestal, Curitiba, PR - Brasil. E-mail:

$<$ lizenflorestal@gmail.com>.
} 


\section{INTRODUÇÃO}

A capacidade do homem em controlar o fogo foi um dos fatores que permitiu à humanidade se desenvolver, formando civilizações e se expandindo por todo o planeta. $\mathrm{O}$ fogo era utilizado para preparar alimentos, para o aquecimento e para a caça. À medida que o domínio do fogo foi evoluindo, os homens perceberam que o uso da madeira carbonizada trazia vantagens nos aspectos de transporte e eficiência energética. Esse combustível não produzia chama nem tanta fumaça, gerando, assim, calor de forma mais controlável.

Mais tarde, o carvão vegetal serviu para o tratamento de material que serviria para a confecção de armas, ferramentas e utensílios, conferindo à lenha a qualificação de sistema energético mais antigo da humanidade (SANTOS; HATAKEYAMA, 2012). Até os dias atuais, o carvão vegetal continua sendo fonte de energia indispensável para a sociedade, sendo alternativa aos combustíveis fósseis e, por esse motivo, seu consumo tenderá a aumentar nos próximos anos.

O Brasil é grande produtor de carvão vegetal, e sua produção corresponde a $1 / 3$ da produção mundial, e a grande parte desse carvão produzido é utilizada na siderurgia (MEIRA et al., 2005; PINHEIRO, 2006; SANTOS; HATAKEYAMA, 2012). A produção de carvão vegetal no Brasil está vinculada intimamente com a produção de ferro-gusa; essa situação acontece em poucos lugares no mundo, pois a maioria dos países substituiu o carvão vegetal pelo mineral. Trata-se de uma atividade de grande importância econômica para o país, que direta ou indiretamente envolve grande número de trabalhadores (PINHEIRO, 2006; SANTOS; HATAKEYAMA, 2012).

O uso siderúrgico ou energético do carvão na indústria da Região Sul do Brasil é pouco significativo. No entanto, quando se fala em uso doméstico se destaca a sua aplicação para o preparo do churrasco, tendo em visto que esse alimento tem grande importância cultural para a população dos Estados do Sul.

Apesar de exemplos mundiais de produção de carvão vegetal com modernos processos industriais e elevados índices tecnológicos, em nosso país a produção ainda é realizada em sua maioria em fornos de alvenaria. Tal prática é considerada primitiva, com descarte de milhares de toneladas de componentes químicos no ar, pois no processo de carbonização se aproveitam apenas de 30 a $40 \%$ da madeira na forma de carvão vegetal (BRITO, 1990; MEIRA et al., 2005.) Portanto, quase toda a sua produção é feita do mesmo modo há quase um século, sem a preocupação com o meio ambiente e com as condições de trabalho (MEIRA et al., 2005; PINHEIRO, 2006; SANTOS; HATAKEYAMA, 2012).

Brito (1990) afirmou que durante a conversão da madeira em carvão vegetal ocorre uma série de outros fenômenos, além da concentração de carbono. Evidentemente que o nível de ocorrência de tais fenômenos está associado ao nível de temperatura que se alcança durante a conversão. De modo geral, são observados diminuição de volume e escurecimento da madeira, abertura e fechamento de poros, fissuração, diminuição da densidade etc.

Por esses motivos, pode-se afirmar que a qualidade do carvão vegetal para o uso doméstico causa insegurança, pois se percebe que o controle da carbonização é difícil na maioria dos fornos, produzindo material heterogêneo, diferindo, principalmente, em densidade, umidade, composição química, friabilidade, resistência mecânica, reatividade e higroscopicidade (COUTINHO; FERRAZ, 1988; ROSA et al., 2012).

Sobre isso, Pennise et al. (2001) e Rosa et al. (2012) ainda afirmaram que tal insegurança se dá porque o processo de carbonização libera, em sua fumaça, mais de 130 substâncias tóxicas, sendo 10 delas classificadas como hidrocarbonetos policíclicos aromáticos (HPAs), que podem causar câncer, mutações genéticas e desregular o sistema endócrino. Então, deve-se saber quais os níveis seguros para se produzir um carvão de qualidade e deve-se, ainda, garantir que tal processo realmente ocorra.

A forma de carbonização do carvão é de extrema importância para que se tenha um carvão de boa qualidade, de forma que o consumidor possa usar o mesmo em sua residência sem maiores preocupações. Porém, um grande entrave para que isso ocorra é a forma com que grande parte desse carvão ainda é produzida, devendo o setor público, juntamente com o privado, achar soluções para que tais problemas sejam sanados ou amenizados.

Para o carvão vegetal ser considerado de boa qualidade, é necessário analisar algumas características, como: alto poder calorífico; baixa umidade; e baixo

Revista Árvore, Viçosa-MG, v.39, n.6, p.1165-1173, 2015 
teor de materiais voláteis e baixo teor de cinzas (RIBEIRO EVALE, 2006; ROSA et al., 2012).

Segundo Rosa et al. (2012), para determinar o padrão de qualidade do carvão vegetal, considerando: propriedades como teor de carbono fixo, teor de materiais voláteis e teor de cinzas; práticas de processamento; faixa de tolerância para o tamanho das peças de carvão vegetal embalado; tipo preferencial de embalagem; e a origem do produto e intervalos de tolerância foram criados em 2003, no Estado de São Paulo, o Selo Premium, promulgado pela Resolução ${ }^{\circ} 10 \mathrm{SAA}$, de 11 de julho de 2003. Segundo essa Resolução, a umidade do carvão vegetal deve estar abaixo de $5 \%$, o teor de carbono fixo (TCF) deve ser maior que $75 \%$ e o teor de materiais voláteis (TMV) e o teor de cinzas devem ser menores que $23,5 \%$ e $1,5 \%$, respectivamente.

Levando em consideração que o carvão vegetal para uso doméstico é um combustível para fogões à lenha, lareiras, churrasqueiras e outros gêneros, seria interessante que, assim como o Estado de São Paulo, que criou o Selo Premium, outros Estados, como Santa Catarina, seguissem a mesma ideia, para, dessa forma, padronizar a produção do carvão e garantir maior segurança ao consumidor.

Portanto, no intuito de fornecer informações para o poder público, sobre a qualidade do carvão comercializado em Santa Catarina, de modo a subsidiar a criação de normativas para o controle de qualidade do carvão de uso doméstico no Estado, este trabalho teve como objetivo averiguar a qualidade do carvão vegetal, para o consumo doméstico, comercializado na região Serrana Sul de Santa Catarina.

\section{MATERIAL E MÉTODOS}

O estudo foi realizado na região Serrana Sul de Santa Catarina, pertencente à Associação dos Municípios da Região Serrana (AMURES). Os municípios pertencentes a AMURES são: Anita Garibaldi, Bocaina do Sul, Bom Jardim da Serra, Bom Retiro, Campo Belo do Sul, Capão Alto, Cerro Negro, Correia Pinto, Lages, Otacílio Costa, Painel, Palmeira, Ponte alta, Rio Rufino, São Joaquim, São José do Cerrito, Urubici e Urupema. Entre esses, os compreendidos no estudo foram: Lages, Urubici, Campo Belo do Sul, Capão Alto, Cerro Negro, Anita Garibaldi e Curitibanos. Este último não pertence a AMURES, porém foi incluído nos estudos, devido à sua importância regional.
Para a compra das amostras de carvão, foram estabelecidos alguns critérios de seleção, como: preços (baixo, médio e alto), o nível socioeconômico da população atendida por cada estabelecimento comercial amostrado e a variabilidade das marcas nos estabelecimentos. Também, foram registrados os dados e as características de cada embalagem, como preço, data de fabricação, registro em órgãos ambientais estaduais e federais, endereço completo, fabricante, presença de acendedor, origem do carvão (espécies), peso ou volume, número de lote e outras observações importantes. Devido ao fato de as marcas apresentarem diferentes pesos para comercialização, adotou-se a compra de pelo menos $8 \mathrm{~kg}$ e, ou, pelo menos duas embalagens de cada marca, algumas necessitando da compra de mais de duas embalagens para atingir o peso mínimo determinado para análise.

Foram visitados 18 estabelecimentos comerciais, sendo em oito deles situados nos Municípios de Lages, Urubici e Curitibanos, compradas 12 marcas de carvão para as análises em laboratório. Nos Municípios de Anita Garibaldi, Campo Belo, Capão Alto e Cerro Negro não foram compradas amostras diferentes, pois nos estabelecimentos desses municípios eram comercializadas as mesmas marcas já antes adquiridas. Nesses locais, foram registrados somente os nomes da marca do carvão e do estabelecimento visitado.

Após a compra do material, este foi encaminhado para o Laboratório de Tecnologia da Madeira do Centro de Ciências Agroveterinárias (UDESC-CAV) da Universidade do Estado de Santa Catarina, em Lages, $\mathrm{SC}$, onde foram armazenados e analisados.

Para cada amostra foi misturado o total de sacos de cada marca, dividindo-as em amostras de $500 \mathrm{~g}$ de carvão moído, utilizadas para determinar as propriedades: teor de umidade na base úmida, segundo NBR 14929 (ABNT, 2003); densidade relativa aparente, por meio dos procedimentos descritos na NBR 9165 (ABNT, 1985); poder calorífico, determinado em calorímetro, segundo a Norma DIN 51900 (DIN, 2000); teor de voláteis; teor de carbono fixo; e teor de cinzas em Termobalança Gravimétrica (TGA), conforme a Norma ASTM 1762 (ASTM, 2007), com temperaturas de $900{ }^{\circ} \mathrm{C}$, para determinação dos voláteis e $700{ }^{\circ} \mathrm{C}$ para cinzas.

A análise estatística dos dados foi processada por meio do Assistat, utilizando a análise de variância (teste F) a 5\% de significância e, quando os dados

Revista Árvore, Viçosa-MG, v.39, n.6, p.1165-1173, 2015 
foram significativos, foi empregado o teste de Tukey a $1 \%$ de significância, para comparação das médias.

\section{RESULTADOS}

\subsection{Caracterização geral do carvão comercial}

As informações relativas à origem e ao local de compra das amostras de carvão vegetal analisadas podem ser visualizadas na Tabela 1.

Para cada marca foram encontradas diferentes características contidas nas embalagens, conforme mostrado na Tabela 2 .

\subsection{Qualidade do carvão vegetal comercializado na região Serrana Sul de Santa Catarina}

Nas Tabelas 3 e 4 são apresentadas as propriedades físicas e energéticas do carvão comercializado na região do Planalto Sul catarinense, respectivamente.

\section{DICUSSÕES}

\subsection{Caracterização geral do carvão comercial}

Com relação à origem, os carvões foram produzidos em cidades localizadas, principalmente, no Estado de Santa Catarina (8 marcas); Rio Grande do Sul (2), sendo

Tabela 1 - Origem e local de comercialização das marcas de carvão coletadas na região do Planalto Sul catarinense. Table 1 - Origin and place of marketing the brands of charcoal collected in the Southern Highlands Region of Santa Catarina.

\begin{tabular}{|c|c|c|c|}
\hline $\begin{array}{l}\text { Local de compra } \\
\text { (Município) }\end{array}$ & Estabelecimento & Amostra & Local de fabricação do carvão \\
\hline \multirow[t]{8}{*}{ Lages (LA) } & 1 & A & Grão Pará-SC \\
\hline & & $\mathrm{B}$ & Brochier-RS \\
\hline & 2 & $\mathrm{C}$ & Indaial-SC \\
\hline & & $\mathrm{D}$ & Lages-SC \\
\hline & 3 & $\mathrm{E}$ & Sem identificação na embalagem \\
\hline & & $\mathrm{F}$ & Brochier-RS \\
\hline & 4 & G & Santa Cecília-SC \\
\hline & 5 & $\mathrm{H}$ & Aurora-SC \\
\hline Urubici (U) & 6 & I & Grão Pará-SC \\
\hline Capão Alto (CA) & 7 e 8 & $\mathrm{D}, \mathrm{B}, \mathrm{H}$ & Lages-SC; Brochier-RS; Aurora-SC \\
\hline Anita Garibaldi (AG) & 9 e 10 & $\mathrm{D}, \mathrm{I}, \mathrm{F}, \mathrm{H}$ & Lages-SC; Grão Pará-SC; Brochier-RS; Aurora-SC \\
\hline Otacílo Costa (OC) & 11,12 e 13 & $\mathrm{C}, \mathrm{D}$ e $\mathrm{E}$ & Indaial-SC; Lages-SC; Sem identificação na embalagem \\
\hline \multirow[t]{2}{*}{ Palmeira (PA) } & 14 & $\mathrm{D}$ e $\mathrm{A}$ & Lages-SC; Grão Pará-SC \\
\hline & 15 & J & Concórdia-SC \\
\hline \multirow[t]{2}{*}{ Curitibanos } & 15 & $\mathrm{~K}$ & Lages-SC \\
\hline & 16 & $\mathrm{~L}$ & Colombo-PR \\
\hline Campo Belo (CB) & 17,18 & $\mathrm{D}, \mathrm{H}$ e $\mathrm{E}$ & Lages-SC; Aurora-SC; Sem identificação na embalagem \\
\hline
\end{tabular}

Tabela 2 - Informações das embalagens das marcas de carvão vegetal comercializadas na região do Planalto Sul catarinense. Table 2 - Information on the packaging of brands of charcoal sold in the Southern Highlands Region of Santa Catarina.

\begin{tabular}{|c|c|c|c|c|c|c|c|}
\hline Marca & $\begin{array}{c}\text { Espécies } \\
\text { identificadas }\end{array}$ & Acendedor & $\begin{array}{c}\text { Peso }(\mathrm{kg}) \\
\text { ou volume }\left(\mathrm{m}^{3}\right)\end{array}$ & $\mathrm{N}^{\circ}$ lote & $\begin{array}{c}\text { Preço } \\
\text { unidade }\end{array}$ & \multicolumn{2}{|c|}{$\begin{array}{c}\text { Registro } \\
\text { órgão ambiental }\end{array}$} \\
\hline A & Eucalipto & Não & $3,86 \mathrm{~kg}$ & Não & 11,09 & $\mathrm{~N}$ & $\mathrm{E}$ \\
\hline B & Acácia negra & Não & $5 \mathrm{~kg}$ & Sim & 12,94 & & $\mathrm{E}$ \\
\hline $\mathrm{C}$ & Acácia negra & Não & $5 \mathrm{~kg}$ & Não & 12,85 & $\mathrm{~N}$ & $\mathrm{E}$ \\
\hline $\mathrm{D}$ & Eucalipto & Sim & $4,176 \mathrm{~kg}$ & Não & 14,68 & $\mathrm{~N}$ & \\
\hline $\mathrm{E}$ & Acácia negra & Sim & $3 \mathrm{~kg}$ & Não & 7,39 & $\mathrm{~N}$ & $\mathrm{E}$ \\
\hline $\mathrm{F}$ & Acácia negra & Sim & $4 \mathrm{~kg}$ & Não & 12,9 & & $\mathrm{E}$ \\
\hline G & Essências florestais diversas & Não & $3 \mathrm{~kg}$ & Não & 7,98 & $\mathrm{~N}$ & $\mathrm{E}$ \\
\hline $\mathrm{H}$ & Misto essências exóticas e nativas & Não & $4,5 \mathrm{~kg}$ & Não & 12,98 & $\mathrm{~N}$ & \\
\hline I & Essências florestais diversas & Não & $0,0016 \mathrm{~m}^{3}$ & Não & 14,75 & $\mathrm{~N}$ & \\
\hline $\mathbf{J}$ & Acácia-negra & Sim & $3 \mathrm{~kg}$ & Não & 9,99 & $\mathrm{~N}$ & $\mathrm{E}$ \\
\hline $\mathrm{K}$ & Carvão especial limpo e granulado & Não & $0,018 \mathrm{~m}^{3}$ & Não & 8,60 & $\mathrm{~N}$ & \\
\hline $\mathrm{L}$ & Eucalipto e Bracatinga plantada & Sim & $4 \mathrm{~kg}$ & Não & 7,99 & $\mathrm{~N}$ & \\
\hline
\end{tabular}

Nota: N - Registro no IBAMA; e E - Registro no órgão estadual.

Revista Árvore, Viçosa-MG, v.39, n.6, p.1165-1173, 2015 
somente uma marca oriunda do Paraná. Em uma das marcas não havia identificação do local de produção.

Segundo Riegelhaupt e Pareyn (2010), no caso da lenha, o custo do transporte em relação ao valor do produto é alto, assim as distâncias entre produtores e consumidores normalmente não ultrapassam $300 \mathrm{~km}$. No caso do carvão vegetal, cujo custo de transporte é menor em relação ao preço final, é comum encontrar fluxos com preços compensatórios a grandes distâncias, de até $800 \mathrm{~km}$ ou mais. Portanto, para este estudo, as distâncias entre produtores e consumidores podem ser consideradas baixas, tendo em vista que a distância entre o local de produção do carvão e os consumidores variou de $38 \mathrm{~km}$ (Lages a Palmeira, ambos em SC) até 352 km (Bolchier-RS a Anita Garibaldi-SC).

As duas marcas mais comercializadas na região são produzidas na própria região: Lages (marca D) e Aurora $(\mathrm{H})$, sendo esta última cidade distante $234 \mathrm{~km}$ de Anita Garibaldi, a cidade mais distante atendida pela marca.

A espécie mais utilizada para a produção do carvão foi a acácia-negra (Acacia mearnsii), presente em cinco marcas avaliadas, seguida das espécies do gênero Eucalyptus. As duas marcas oriundas do Rio Grande do Sul são de acácia-negra, sendo compatível com a

Tabela 3 - Propriedades físicas do carvão vegetal comercializado na região do Planalto Sul de Santa Catarina. Table 3 - Physical properties of charcoal sold in the Southern Highlands Region of Santa Catarina.

\begin{tabular}{ccc}
\hline Amostra & Densidade relativa aparente $\left(\mathrm{g} / \mathrm{cm}^{3}\right)$ & Umidade $(\%)$ \\
\hline A & $0,488 \mathrm{a}$ & $8,21 \mathrm{ab}$ \\
B & $0,400 \mathrm{f}$ & $7,00 \mathrm{bcd}$ \\
C & $0,447 \mathrm{c}$ & $6,94 \mathrm{bcd}$ \\
D & $0,359 \mathrm{~h}$ & $8,19 \mathrm{ab}$ \\
E & $0,465 \mathrm{~b}$ & $6,96 \mathrm{bcd}$ \\
F & $0,465 \mathrm{~b}$ & $5,59 \mathrm{~d}$ \\
G & $0,295 \mathrm{i}$ & $8,59 \mathrm{a}$ \\
H & $0,245 \mathrm{j}$ & $7,62 \mathrm{abc}$ \\
I & $0,413 \mathrm{e}$ & $8,44 \mathrm{a}$ \\
J & $0,442 \mathrm{~d}$ & $6,20 \mathrm{~cd}$ \\
K & $0,376 \mathrm{~g}$ & $7,65 \mathrm{ab}$ \\
L & $0,446 \mathrm{c}$ & $6,78 \mathrm{bcd}$ \\
Média & $\mathbf{0 , 4 0 3}$ & $\mathbf{7 , 3 5}$ \\
\hline
\end{tabular}

Nota: Médias seguidas da mesma letra na coluna não diferem estatisticamente (Tukey, $\mathrm{p}<0,01$ ).

Tabela 4 - Propriedades energéticas do carvão vegetal comercializado na região do Planalto Sul de Santa Catarina. Table 4 - Energetic properties of charcoal sold in the Southern Highlands Region of Santa Catarina.

\begin{tabular}{|c|c|c|c|c|}
\hline Amostra & PCS (kcal/kg) & TMV (\%) & TCF (\%) & TCZ (\%) \\
\hline A & $7944 \mathrm{~b}$ & $29,26 \mathrm{~cd}$ & $66,85 \mathrm{bc}$ & 3,89 a \\
\hline $\mathrm{B}$ & $7448 \mathrm{e}$ & $35,76 \mathrm{~b}$ & $63,43 \mathrm{~cd}$ & 0,81 ef \\
\hline $\mathrm{C}$ & $6688 \mathrm{~h}$ & $39,46 \mathrm{~b}$ & $59,86 \mathrm{de}$ & $0,68 \mathrm{f}$ \\
\hline $\mathrm{D}$ & $4458 \mathrm{k}$ & $31,10 \mathrm{c}$ & $67,06 \mathrm{~b}$ & $1,85 \mathrm{~cd}$ \\
\hline $\mathrm{E}$ & $7578 \mathrm{c}$ & $28,53 \mathrm{~cd}$ & $69,90 \mathrm{~b}$ & $1,57 \mathrm{de}$ \\
\hline $\mathrm{F}$ & $7029 \mathrm{~g}$ & $44,69 \mathrm{a}$ & $54,24 \mathrm{f}$ & 0,89 ef \\
\hline G & 43011 & $27,67 \mathrm{~cd}$ & $68,79 \mathrm{ab}$ & $3,44 \mathrm{ab}$ \\
\hline $\mathrm{H}$ & $4486 \mathrm{j}$ & $28,24 \mathrm{~cd}$ & $70,07 \mathrm{ab}$ & $1,69 \mathrm{de}$ \\
\hline I & $7547 \mathrm{~d}$ & $26,42 \mathrm{~d}$ & $70,85 \mathrm{a}$ & $2,73 \mathrm{bc}$ \\
\hline $\mathbf{J}$ & $7208 \mathrm{f}$ & $37,42 \mathrm{~b}$ & $61,66 \mathrm{de}$ & 0,92 ef \\
\hline $\mathrm{K}$ & 7968 a & $26,15 \mathrm{~d}$ & $71,21 \mathrm{a}$ & $2,64 \mathrm{c}$ \\
\hline $\mathrm{L}$ & $4736 \mathrm{i}$ & $39,47 \mathrm{~b}$ & 58,12 ef & $2,42 \mathrm{~cd}$ \\
\hline Média & 6449 & 32,85 & 65,17 & 1,96 \\
\hline
\end{tabular}

Nota: Médias seguidas da mesma letra na coluna não diferem estatisticamente (Tukey, p $<0,01$ ). PCS - poder calorífico superior; TMV - teor de material volátil; TCF - teor de carbono fixo; e TCZ - teor de cinzas. 
afirmação de Madail e Sima (2011), que constaram que quase toda a produção de carvão vegetal, no Rio Grande do Sul, é originária de floresta plantada de eucalipto e de acácia-negra e destinada ao consumo doméstico.

Sete das marcas avaliadas tinham acendedor, enquanto as outras cinco não tinham esse acessório. Não parece haver relação entre a presença do acendedor e o preço do carvão. No entanto, este item pode ser considerado um diferencial de qualidade no produto, por facilitar a ignição do carvão.

Com relação à quantidade de carvão contida na embalagem, pode-se constatar a falta de padronização, tanto da unidade de medida quanto da quantidade na embalagem. As unidades de medida foram peso e volume, e cada fabricante determina a quantidade a ser colocada na embalagem. Esse fator é prejudicial para a análise do consumidor, quando este deseja comparar preço e quantidade de produção entre diferentes marcas. $\mathrm{O}$ preço médio de venda do carvão na região foi de $\mathrm{R} \$$ 11,30 , com grande variação entre marcas e quantidade de produto na embalagem.

As embalagens também não permitem a rastreabilidade do produto, pois somente uma marca continha número do lote de produção. Todas as marcas possuíam registro nos órgãos de fiscalização ambiental: no IBAMA (10 marcas) ou nos órgãos estaduais (FATMA ou SEMA) (sete marcas), ou em ambos os órgãos (cinco marcas).

Dessa forma, poder observar que não existe padronização das embalagens quanto à: quantidade de carvão nas embalagens, unidade de medida da quantidade de produto, existência do número do lote de produção e presença de acessórios como acendedor.

\subsection{Qualidade do carvão vegetal comercializado na região Serrana Sul de Santa Catarina}

A densidade relativa aparente média do carvão obtida neste trabalho foi alta e similar ao citado por Trugilho et al. (2001), que em 10 clones de Eucalyptus encontrou o valor médio de $0,448 \mathrm{~g} / \mathrm{cm}^{3}$. Pimenta e Barcelos (2000) mencionaram valores genéricos para carvão vegetal de $0,46 \mathrm{~g} / \mathrm{cm}^{3}$. Valores próximos também foram constatados por Rosa et al. (2012), que avaliaram a qualidade do carvão de uso doméstico comercializado em três Municípios do Espírito Santo, onde obteve 0,377;0,373; e 0,379 g/ $\mathrm{cm}^{3}$. Já Frederico (2009), trabalhando com Eucalyptus grandis e híbridos de Eucalyptus grandis x Eucalyptus urophylla, encontrou valores de densidade aparente de carvão vegetal entre 0,285 e $0,323 \mathrm{~g} / \mathrm{cm}^{3}$, inferiores aos encontrados neste estudo.

Nas marcas avaliadas, as maiores densidades foram observadas no carvão produzido a partir de eucalipto e acácia-negra e os menores, no carvão de essências florestais diversas. As amostras E e F (acácia-negra) e C e L (acácia-negra e eucalipto com bracatinga) foram iguais estatisticamente entre si e todas as demais, diferentes entre si.

O teor de umidade médio das amostras foi alto para uso doméstico, considerando como parâmetro de comparação o valor estabelecido pelo Selo Premium, promulgado pela Resolução ${ }^{\circ} 10$ SAA, de 11 de julho de 2003, no Estado de São Paulo (SÃO PAULO, 2003), que determina que a umidade do carvão vegetal deve estar abaixo de $5 \%$.

O valor médio de umidade observado foi maior que os apresentados por Brand et al. (2013), que determinaram a qualidade do carvão vegetal de Miconia cinnamomifolia, produzido em Santa Catarina, e encontraram valores médios de 5,5\% do teor de umidade. Rosa et al. (2012), em amostras de várias origens, também encontraram teores de umidade que variaram entre 4,17 ; 4,25; e 5,57\%.

O menor teor de umidade foi registrado na amostra F (acácia-negra) e o maior na amostra G (diversas espécies). Houve grande variação entre as amostras, demonstrada pela análise estatística.

O poder calorífico superior médio do carvão foi baixo e similar ao observado por Brand et al. (2013), que encontraram valores de $6.267 \mathrm{kcal} / \mathrm{kg}$ para carvão de Miconia cinnamomifolia, produzidos em Santa Catarina.

Protazio et al. (2011), avaliando diferentes posições longitudinais no tronco para carvão, o vegetal de Qualeaparvifolia encontraram valores médios de poder calorífico superior de $7.388,7 \mathrm{kcal} / \mathrm{kg}$, enquanto Rosa et al. (2012), para amostras de carvão de uso doméstico, de diferentes origens, encontraram valores de 7.400 a $7.800 \mathrm{~kg} / \mathrm{kg}$. Neves et al. (2011) depararam com valores de 7.643 e $7.665 \mathrm{kcal} / \mathrm{kg}$ para o carvão de clones de Eucalyptus de diferentes procedências. Já Barcellos (2007) encontrou valores de 6.963, 7.462 e $7.830 \mathrm{kcal} /$ kg para clones de Eucalyptus grandis trabalhando com temperaturas finais de $350{ }^{\circ} \mathrm{C}, 450^{\circ} \mathrm{C}$ e $550^{\circ} \mathrm{C}$, 
respectivamente, e tempo de exposição a cada temperatura igual para todas as marchas de carbonização.

Esses valores mais altos, encontrados por Protazio et al. (2011), Rosa et al. (2012), Neves et al. (2011) e Barcellos (2007), foram similares às amostras A (eucalipto), B, E, F e J (acácia-negra), I (espécies diversas) e K (sem identificação).

Os menores valores foram observados nas amostras D (eucalipto), G e H (espécies diversas) e L (eucalipto + bracatinga). Esses valores mais baixos, entre 4.000 e $4.700 \mathrm{kcal} / \mathrm{kg}$ (amostras D, G, H e L), próximos aos encontrados para madeira, indicaram que a carbonização não foi mal realizada.

O poder calorífico teve grande variação entre as amostras analisadas, sendo todas as diferentes entre si, estatisticamente.

A composição química imediata demonstrou que as amostras de carvão tinham altos teores de voláteis e de cinzas e baixo conteúdo de carbono fixo. Alto teor de materiais voláteis (TMV) no carvão resulta em grande liberação de substâncias tóxicas, desprendidas durante a queima, que o torna prejudicial à saúde humana (BRAHAN, 2002).

O Selo Premium destaca que o teor de carbono fixo (TCF) deve ser superior a $75 \%$; teor de materiais voláteis (TMV), e o teor de cinzas devem ser inferiores a 23,5\% e 1,5\%, respectivamente (SÃO PAULO, 2003).

Brand et al. (2013) obtiveram valores médios de $68,18 \%$ de carbono fixo, teor de voláteis de $30,47 \%$ e $1,35 \%$ de teor de cinza no carvão de Miconia cinnamomifolia. Entretanto, Rosa et al. (2012) obtiveram valores entre 75 e $83 \%$; 15 e $23 \%$; e 0,68 e $1,65 \%$ para teor de carbono fixo, voláteis e cinzas, respectivamente. Neves et al. (2011) encontraram valores entre 79,92 e $80,29 \%$ de carbono fixo, 18,92 e $19,43 \%$ de voláteis e teor de cinzas entre 0,65 e $0,80 \%$ no carvão de clones de Eucalyptus.

Os valores médios obtidos neste trabalho foram inferiores ao observado na literatura, e nenhuma marca cumpre o critério de qualidade do carvão para uso doméstico, segundo o Selo Premium para voláteis e carbono fixo. Somente os carvões de acácia-negra cumprem o limite máximo de teor de cinzas exigido.

Também houve grande variação estatística entre as amostras. Nos voláteis, os valores mais altos foram observados no carvão de acácia-negra e o menor, no carvão de espécies diversas. O carbono fixo foi maior nos carvões de espécies diversas e o menor, na acácianegra.

\section{CONCLUSÃO}

A produção e consumo do carvão vegetal no Planalto Sul catarinense é regionalizada com proximidade geográfica entre os produtores e consumidores, favorecendo positivamente o comércio do produto.

As embalagens utilizadas para a comercialização do produto não são padronizadas, dificultando a decisão de compra do consumidor.

As essências florestais mais utilizadas para a produção do carvão são oriundas de plantios florestais, principalmente de Acacia mearnsii e das espécies do gênero Eucalyptus, diminuindo a pressão sobre as essências nativas.

Todas as marcas comercializadas possuem registro nos órgãos de fiscalização ambiental (Federal e, ou, Estadual), indicando regulamentação na produção e comércio, mas sem rastreabilidade, por ausência de número de lote ou outra ferramenta de controle do processo de produção.

O carvão analisado tem baixa qualidade para uso doméstico por apresentar altos teores de umidade, voláteis e cinzas e baixos valores de poder calorífico superior e carbono fixo.

A variação entre as amostras, quanto às propriedades físicas e energéticas do carvão, também evidenciam a baixa qualidade do produto produzido e comercializado na região.

\section{REFERÊNCIAS}

\section{ASSOCIAÇÃO BRASILEIRA DE NORMAS} TÉCNICAS - ABNT. NBR 9165 -

Determinação da densidade relativa aparente, relativa verdadeira e porosidade. Rio de Janeiro:1995.

\section{ASSOCIAÇÃO BRASILEIRA DE NORMAS} TÉCNICAS - ABNT. NBR 14929: Madeira Determinação do teor de umidade de cavacos Método por secagem em estufa. Rio de Janeiro: 2003.

Revista Árvore, Viçosa-MG, v.39, n.6, p.1165-1173, 2015 


\section{AMERICAN SOCIETY FOR TESTING AND MATERIAL - ASTM. Standard Test Method for Chemical Analysis of Wood Charcoal.D $1762-84,2001$ (2007). West Conshohocken, PA: ASTM International, 2007.}

BARCELLOS, D.C. Caracterização do carvão vegetal através do uso de espectroscopia no infravermelho próximo. 2007. 139f. Tese (Doutorado em Ciência Florestal) - Universidade Federal de Viçosa. Viçosa, MG, 2007.

BRAHAN, W.K. Combustibilidad de la madera: la experiência com espécies colombianas. Bogotá: Fondo de Publicaciones, 2002.

BRAND, M. A.; DA CUNHA, A. B.; DE CARVALHO, A. F.; BREHMER, D. R.; KÜSTER, L. C. Análise da qualidade da madeira e do carvão vegetal produzido a partir da espécie Miconia cinnamomifolia (De Candolle) Naudin (Jacatirão-açu) na agricultura familiar, em Biguaçu, Santa Catarina. Scientia Forestalis, v.41, n.99, p.401-410, 2013.

BRITO. J.O. Princípios de produção e utilização de carvão vegetal de madeira. Documentos Florestais, n.9, p.1-19, 1990.

COUTINHO, A.R.; FERRAZ, E.S.B.

Determinação da friabilidade do carvão vegetal em função do diâmetro das árvores e temperatura de carbonização. IPEF, v.38, p.33-37. 1988.

DEUTSCHES INSTITUT FÜR NORMUNG - DIN. DIN 51900: Determining the gross calorific value of solid and liquid fuels using the bomb calorimeter, and calculation of net calorific value. Berlim: 2000

FREDERICO, P.G.U. Influência da densidade e composição química da madeira sobre a qualidade do carvão de Eucalyptus grandis W. Hill exMaiden e de híbridos de Eucalyptus grandis $\mathrm{x}$ Eucalyptus urophylla S.T. Blake. 2009. $75 \mathrm{f}$. Dissertação (Mestrado em Ciência Florestal) Universidade Federal de Viçosa, Viçosa, MG, 2009.

Revista Árvore, Viçosa-MG, v.39, n.6, p.1165-1173, 2015
MADAIL J.C.M.; SIMA, F.L. Análise econômico-financeira da produção de carvão vegetal no Rio Grande do Sul. Pelotas: 2011.p.7. (Comunicado técnico, 264)

MEIRA, A. M. D.; BRITO, J. O.; RODRIGUEZ, L. C. E. Estudo de Aspectos técnicos, econômicos e sociais da produção de carvão vegetal no Município de Pedra Bela, São Paulo, Brasil. Revista Árvore, v.29, n.5, p.809-817, 2005.

NEVES, T. A.; DE PAULA PROTÁSIO, T.; COUTO, A. M.; TRUGILHO, P. F.; SILVA, V. O.; VIEIRA, C. M. M. Avaliação de clones de Eucalyptus em diferentes locais, visando à produção de carvão vegetal. Pesquisa Florestal Brasileira, v.31, n.68, p.319-330, 2011.

PENNISE, D. M.; SMITH, K. R.; KITHINJI, J. P.; REZENDE, M. E.; RAAD, T. J.; ZHANG, J., FAN, C. Emissions of greenhouse gases and other airborne pollutants form charcoal making in Kenya and Brazil. Journal of Geophysical Research, v.106, n.20, p.24143-24155, 2001.

PIMENTA, A.S.; BARCELLOS, D.C. Curso de atualização e carvão vegetal. Viçosa, MG: Centro de Produções técnicas - CPT, 2000. p.76.

PINHEIRO, P.C.C. A produção de carvão vegetal: teoria e prática. Belo Horizonte: 2006.

DE PAULA PROTÁSIO, T.; DE SANTANA, J. D. D. P.; NETO, R. M. G.; JÚNIOR, J. B. G.; TRUGILHO, P. F.; RIBEIRO, I. B. Avaliação da qualidade do carvão de Qualea parvifolia. Pesquisa Florestal Brasileira, v.31, n.68, p.295-307, 2011.

RIBEIRO, P.G.; VALE, A.T. Qualidade do carvão vegetal de resíduos de serraria para o uso doméstico. In: REUNIÃO ANUAL DA SOCIEDADE BRASILEIRA PARA O PROGRESSO DA CIÊNCIA, 2006, Florianópolis. Anais... Florianópolis: 2006.

RIEGELHAUPT, E.M.; PAREYN, F.G.C. A questão energética. In: Uso sustentável e conservação dos recursos florestais da Caatinga. Brasília, D.F., Serviço Florestal Brasileiro, 2010. p.65-75.

ROSA, R. A.; CHAVES ARANTES, M. D.; PAES, J. B.; ANDRADE, W. S. D. P.; MOULIN, J. C. 
Qualidade do carvão vegetal para o consumo doméstico. Journal of Biotechnology and Biodiversity, v.3, n.2, p.41-48, 2012.

SANTOS, S.F.O.M.; HATAKEYAMA, K. Processo sustentável de produção de carvão vegetal quanto aos aspectos: ambiental, econômico, social e cultural. - Salvador-BA. Produção, v.22, n.2, p.309-321, 2012.
SÃO PAULO (Estado). Secretaria de Agricultura e Abastecimento de São Paulo. Resolução n'10 SAA, de 11 de julho de 2003. São Paulo: 2003.

TRUGILHO, P. F.; LIMA, J. T.; MORI, F. A.; LINO, A. L. Avaliação de clones de Eucalyptus para produção de carvão vegetal. Cerne, v.7, n.2, p.104-114, 2001. 
